\title{
Essais
}

Revue interdisciplinaire d'Humanités

$12 \mid 2017$

Textes et contextes : entre autonomie et dépendance

\section{Du contexte à la situation au cotexte et à}

l'intertexte

\section{Henri Portine}

\section{(2) OpenEdition}

1 Journals

Édition électronique

URL : http://journals.openedition.org/essais/2603

DOI : $10.4000 /$ essais. 2603

ISSN : 2276-0970

Éditeur

École doctorale Montaigne Humanités

Édition imprimée

Date de publication : 15 juin 2017

Pagination : 17-32

ISBN : 979-10-97024-02-4

ISSN : 2417-4211

Référence électronique

Henri Portine, « Du contexte à la situation au cotexte et à l'intertexte », Essais [En ligne], 12 | 2017, mis en ligne le 12 octobre 2020, consulté le 25 octobre 2020. URL : http://journals.openedition.org/essais/ 2603 ; DOI : https://doi.org/10.4000/essais.2603 


\section{Du contexte à la situation au cotexte et à l'intertexte}

\section{Henri Portine}

\section{Le mot contexte... a besoin de contexte et de corrélats}

L'emploi du mot " contexte " est souvent polysémique et n'a pas toujours la précision requise. Kleiber ${ }^{1}$ le souligne : "la notion de contexte est protéiforme, flexible ». Auer ${ }^{2}$ revendique cette flexibilité qui permet de remodeler le contexte.

Quelles sont les causes de cette "protéiforméité " ? On peut envisager, au moins, cinq cas :

- les usages quotidiens; contexte (d'abord con-texte) en est venu à désigner la situation comme dans le contexte économique actuel (extension sémantique assez banale) ;

- les usages non maîtrisés dans un discours scientifique pour éviter d'entrer dans une analyse fine;

- les usages prospectifs (cette pratique suppose quel'on apporte une solution à un problème tout en fournissant un nouveau problème à résoudre) ;

- les usages scientifiques contrôlés mais non explicités pour éviter de longues répétitions ;

- les usages scientifiques contrôlés explicites (les concepts scientifiques s'affinent et se recomposent : un usage scientifique dépend de l'époque et des objectifs visés).

Le caractère diffus d'une notion peut ainsi être dû à plusieurs facteurs. Dans le cas de la notion de contexte, il est important d'accepter que le langage et les langues, qui en constituent le substrat central, soient un bien partagé par

1 Kleiber G., "D'un contexte à l'autre : Aspects et dimensions du contexte ", L'information grammaticale, 123 (2009), p. 17-32. La citation se trouve page 17.

2 Page 21 de : Auer P., "Introduction: John Gumperz' Approach to Contextualization ", in Auer P. \& A. Di Luzio (eds), The Contextualization of Language, Amsterdam, John Benjamins, 1992, p. 1-37. 